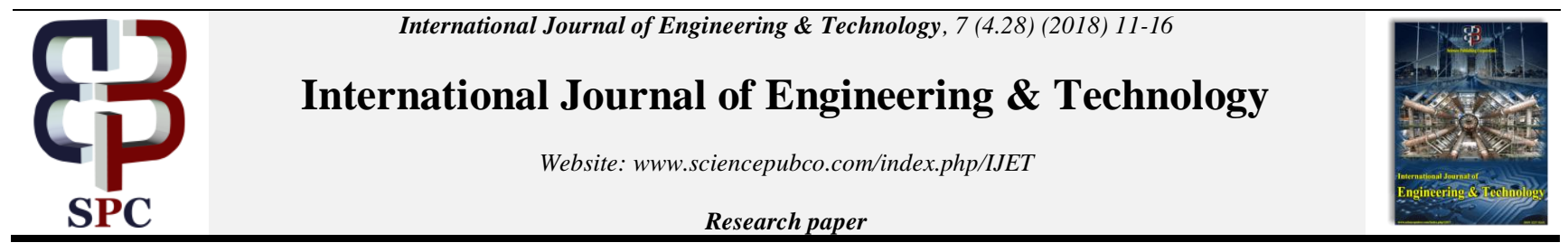

\title{
Financial Control Techniques Services Company with Fuzzy Mamdani
}

\author{
Hari Marfalino ${ }^{\text {a, }}$ Muhammad Reza Putra ${ }^{\text {b, }}$ Guslendra $^{\text {c, }}$ Yosi Yulia ${ }^{\text {d }}$ \\ Computer Science Faculty, Universitas Putra Indonesia “YPTK” Padang, Indonesia \\ Economic Faculty, Universitas Putra Indonesia "YPTK” Padang, Indonesia \\ *Corresponding author Email: hari.marfalino@ upiyptk.ac.id
}

\begin{abstract}
Service Company is a business activity that provides products in the form of services to customers. Micro business services are in great demand among SMK graduates as it is very easy to live up to their abilities. This includes Micro Service Counter service, tai lor, reflection, and others. However, the problem that arises is their lack of practical financial business knowledge. Many businesses they experience an emergency because they do not have proper business financial statements. With the current technological advances, most problems can be solved by technology. One such solution is an accounting information system application with mamdani blur technique. The process of calculating the system is done in 4 stages, namely: the formation of the blur set, the implications of the rules, the rules of composition and Defuzzyfication. Based on the results of trials, there's an error in determining the price of services. Therefore, the high price of service can reduce the number of service requests and the low price service may incur losses to the company. With this system, one can determine the best service price and the best service for consumers.
\end{abstract}

Keywords: Accounting Information System or service company, fuzzy mamdani.

\section{Introduction}

Current technological developments have resulted in all human activities using technology for ease of work. (Ogedengbe \& Agana, 2017). almost all fields of work use technology for daily activities such as medical, industrial, household, government, military that desperately need communication technology. (Ogedengbe \& Agana, 2017).

A service company is a company whose activities include selling or providing services to other parties. Micro services are in high demand among the high school graduates in accordance with their abilities. This includes mobile phones and vehicles service, tailor, car wash and others. Due to limited knowledge, many entrepreneurs do not understand accurate financial calculations and therefore commit service pricing errors. financial statements are needed to determine the development of a company and can be used as material for decision making for the leadership of the company. (Lekhanya, 2013).

In recent years the development of technology has progressed very dramatically. From the 1980 s to the present day, all jobs from small companies or large companies have been replaced by computers. With the presence of a computer, it greatly determines the development of a company such as the production process and increases business costs. Therefore spending on technology must get good supervision because without good supervision will have an adverse impact on the company's finances, especially for small companies around the world. (Arcilla, Calvo-Manzano, \& San Feliu, 2013).

A Fuzzy Inference System (FIS) using knowledge of fuzzy inference devices can provide solutions for information and produce formulations. Fuzzy logic is the concept of partial truth which shows when the proposition is true (Ogedengbe \& Agana, 2017). The Mamdani method has proven to be very appropriate for simulating human reasoning because it formalizes expert knowledge by synthesizing a set of language rules later. we use this method because of its simplicity from natural language (Sanchez-Torrubia \& Torres-Blanc, 2010).

Errors in determining the price of services can cause major problems for service companies. Low service prices provided by the company can cause losses and high speed can reduce the interest of customers to use the service. All the problems that may exist can be overcome with the current technology is financial applications and services using the fuzzy mamdani method.. To produce a more accurate observation method, an accounting information system using Fuzzy Mamdani method which is expected to accelerate the decision of the company in determining the price of services and the best service to the customer is required. This research also built a financial application using Visual basic 2010. Based on the above, the authors performed a research using fuzzy mamdani method to determine the best price and services using matlab applications and build financial applications with the 2010 visual basic programming language.

Copyright $(\odot) 2018$ Authors. This is an open access article distributed under the Creative Commons Attribution License, which permits unrestricted use, distribution, and reproduction in any medium, provided the original work is properly cited. 


\section{Review Literature}

Fuzzy Logic was discovered in 1965 by Lofti A. Zadeh. The basis of fuzzy logic is the set of fuzzy which is a fuzzy result. Fuzzy logic is the logical development of classical logic. The difference between fuzzy logic can be seen in the correct range of values. In a logic pattern of values there are only two people: set members or not, true or false, 0 or 1 . Meanwhile, in fuzzy logic, the average value depends on the membership value. (Agus Nursikuwagus, 2017). Fuzzy process can be seen in Figure 1. Each block has a particular meaning regarding the process it does.

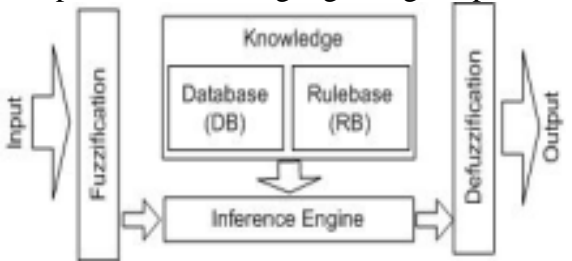

Fig 1: Block Diagram in Fuzzy System Process (Bergmeir \& Ben, 2015)

The fuzzy mamdani method was first used for controller design. Two input variables whose values are defined as fuzzy sets. This variable has range resolution. The output variable is also determined by the fuzzy set (Adewuyi, 2012).

According to Agwu and Carter (2014) and Liaquat et al. (2017), price is the only value to get income and a value given to a product. Furthermore, the price is the amount of value assigned to the product or service. (Faith \& Edwin, 2014). Price is an element in the marketing mix, which plays a very significant role because marketers use price as a means of communicating with customers, through which the message is clearly perceived by customers as intended by marketers (Shaharudin, Angely, Anita, \& Khin, 2012).

\subsection{Fuzzy Inference System Structure}

In general, the fuzzy inference system consists of four modules such as the following: [2012-5]

- Fuzzification module changes the system input, which is a crunchy number into a fuzzy set. This is done by establishing a membership.

There are several functions used, including:

a) Linear representation.

b) Triangle Curve Representation.

c) Trapezoidal Curve Representation.

d) Shoulder Shape Representation.

- Knowledge base stores the IF-THEN rules provided by experts.

- The inference engine simulates the human reasoning process by making fuzzy inference on input and IFTHEN rules.

The defuzzification module changes the fuzzy set generated by the inference engine into a crisp value.

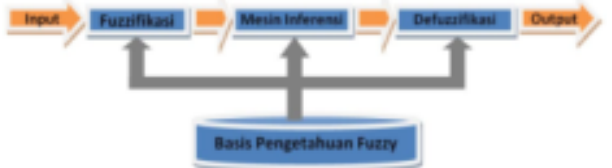

Fig. 2: Fuzzy Inference Scheme Diagram (Sigit \& Kapuji, 2014).

\subsection{Introduction Accounting}

Accounting is the process of identifying, measuring, recording, and communicating the economic activities of a company that will be given to interested parties as a basis for decision making. Internal parties that collect information work for the company and are responsible for planning, managing, and attracting. Areas that can be used as managerial meet the decision making needs of internal parties. External parties do not work for organizations and include investors, creditors, trade unions and customers. Financial accounting is a field that deals with external parties and the needs of external users. (Dauderis \& Annand, 2017).

A company is a group of individuals who unite to carry out joint activities to achieve common goals and objectives. There are two types of business organizations: business and non-business. A business organization sells products and / or services for profit. Non-business organizations, such as charities or hospitals, exist to meet various community needs and do not function as goals. All businesses, regardless of types, records, reports, and, most importantly, use information to make decisions (Dauderis \& Annand, 2017).

\section{Research Methods}

Fuzzy logic is a mathematical system that analyzes analog input values in terms of fuzzy variables that retrieves continuous values between 0 and 1 , in contrast to classical or digital logic, operating with discrete values of either 0 or 1 . Fuzzy logic was first proposed by Lotfi A, Zadeh from the University of California at Barkley in 1965 and the idea was outlined in 1973 which introduced the concept of Fuzzy set. Fuzzy Logic Toolbox, also known as the Graphical User Interface (GUI) tool used to build and edit Fuzzy Interface System (FIS) (Srismrita Basu, 2012). Five GUI tools used for building, editing and observing FIS are:

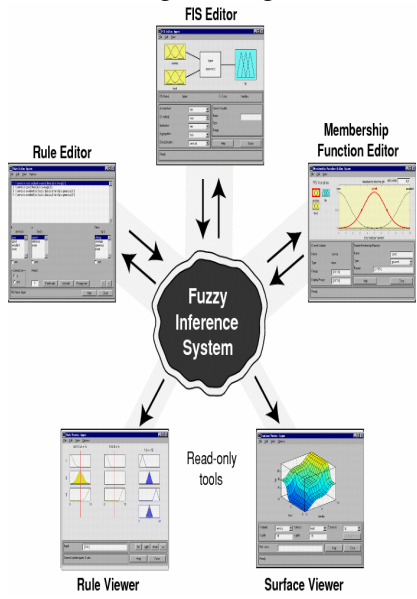

Fig. 3: Fuzzy Logic Toolbox

\section{Result and Discussion}

\subsection{Membership Function Variable Input}

Tabel 1 : Variabel Input

\begin{tabular}{|l|l|l|}
\hline No & Variabel & Unit \\
\hline 1 & Cost & $\mathrm{Rp}$ \\
\hline 2 & Service Process & Minute \\
\hline
\end{tabular}


- Variabel Cost

This cost variable is used to express the cost incurred by the company to perform services to the customer.

Tabel 2 : Cost

\begin{tabular}{|l|l|l|l|}
\hline No & Domain & Tingkat Fuzzy & \multirow{2}{*}{ S.P. } \\
\hline 1 & $15000-25000$ & Rendah & \multirow{2}{*}{$15000-35000$} \\
\hline 2 & $20000-30000$ & Sedang & \\
\hline 3 & $25000-35000$ & Tinggi & \\
\hline
\end{tabular}

Service Process Variable

This service process describes the time required to complete the service.

Tabel 3 : Service Process

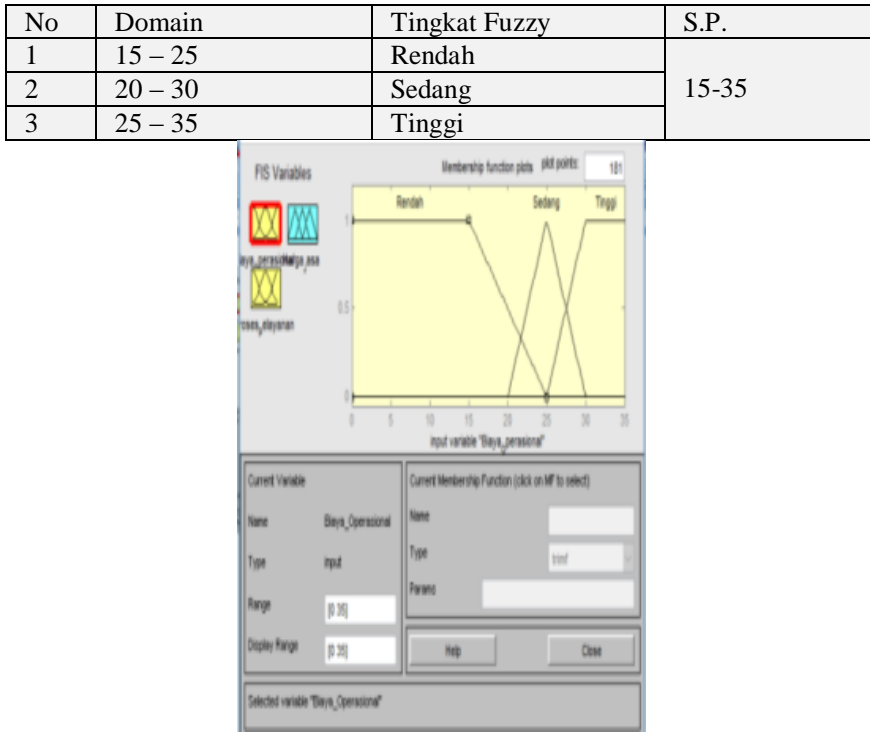

Fig. 4: The fuzzy set of costs

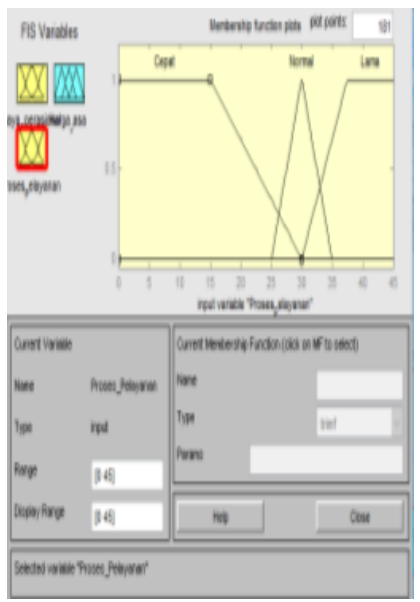

Fig. 5: The Fuzzy set of service Process

\section{Output Variabel}

Variable Service Price is an expected variable in this System. The criteria are based on the research that has been done. Expected results are the best price to get the maximum profit and the best service for the customer.
Tabel 4 : Service Price

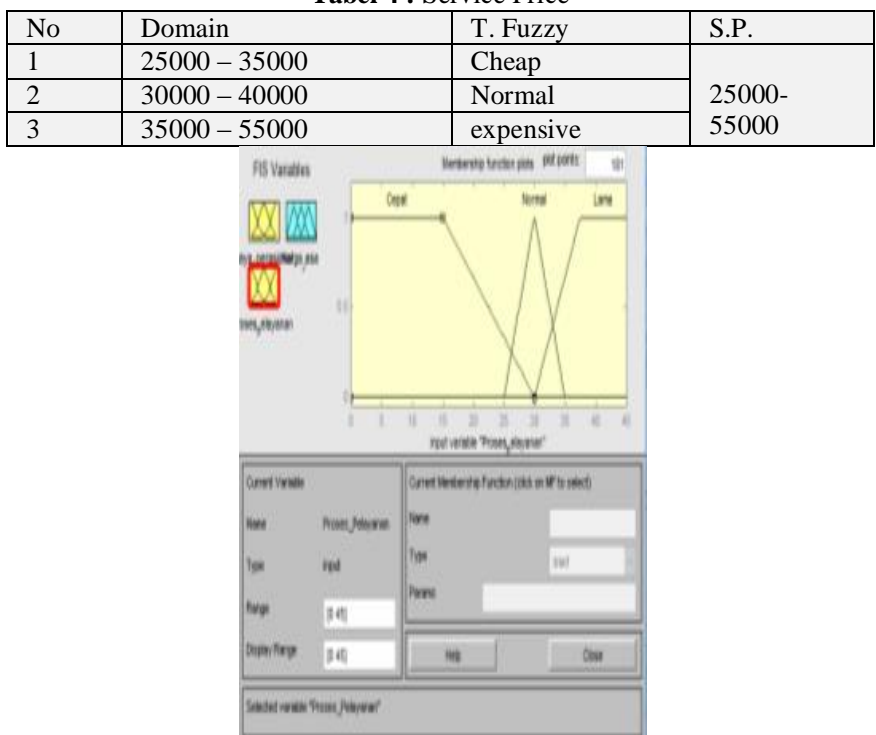

Fig. 6: The Fuzzy Set of Service Prices

\subsection{FIS Editor}

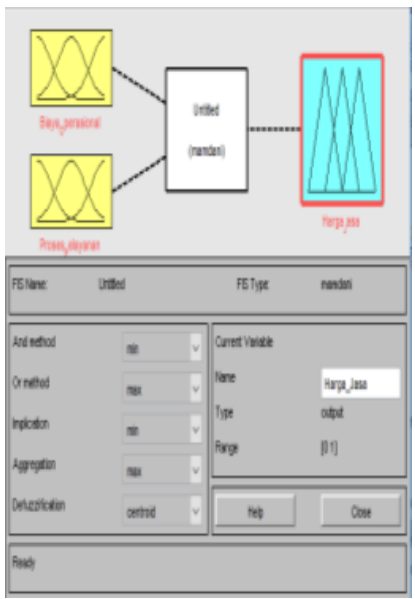

Fig. 7: FIS Editor

\subsection{Rule Editor}

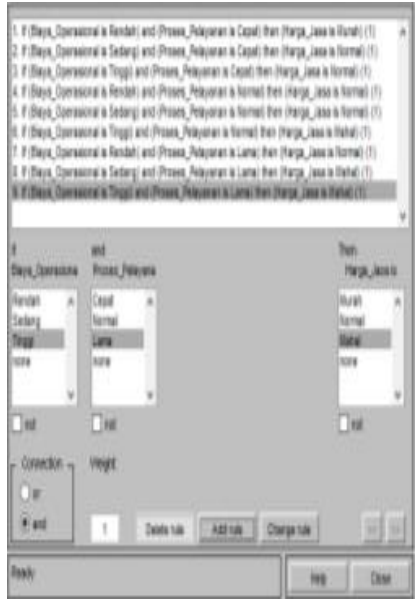

Fig. 8: Rule Editor 


\subsection{Rule Viewer}

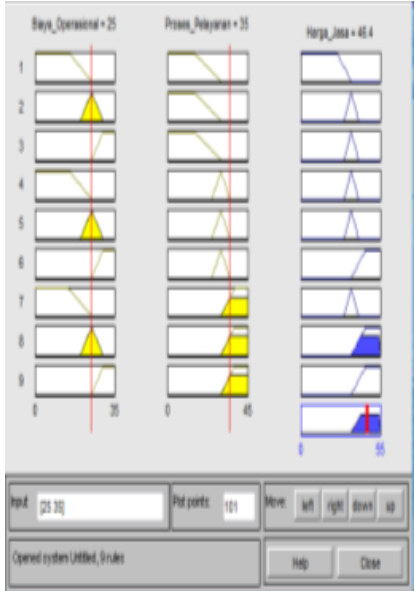

Fig. 9: Rule Viewer

\subsection{Surface Viewer}

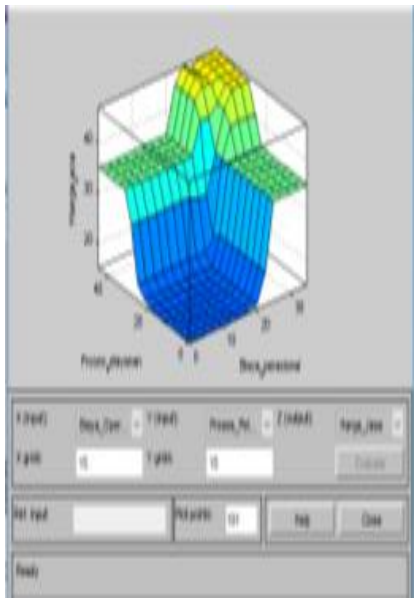

Fig. 10: Surface Viewer

This study used data in August of 2017 at Candelar Wash in Padang, West Sumatera, Indonesia. In this study, the best service price of Rp. 43,000 with the best service process of 55 minutes and Rp. 25.000 operational cost .This research also builds financial applications to produce computerized financial reports. The financial applications that have been built can be seen in the following figure:

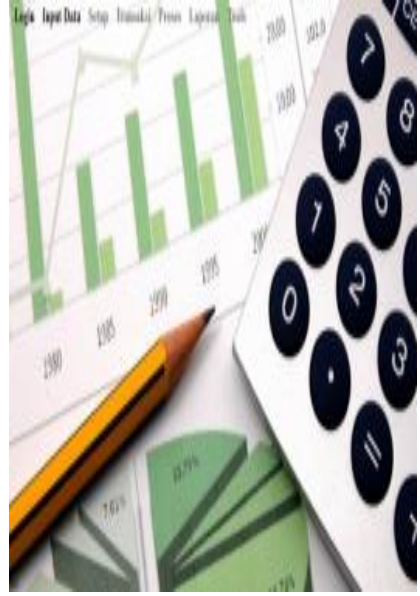

Fig. 11: Menu Utama

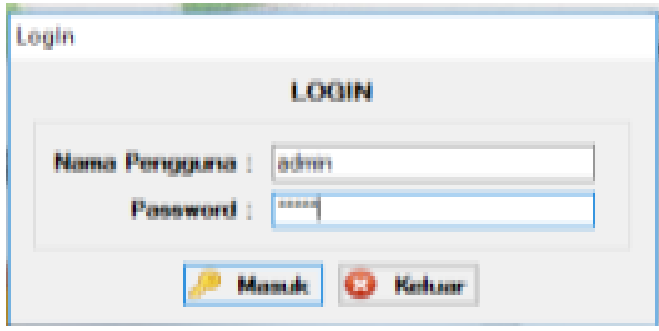

Fig. 12: Display Login Form

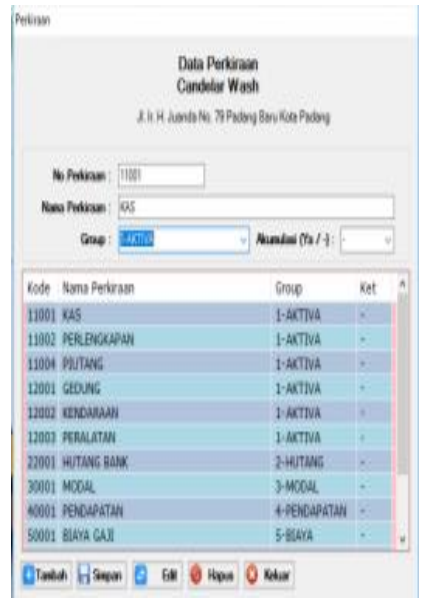

Fig. 13: Display Estimates Form

\section{DAFTAR PERKIRAAN}

\begin{tabular}{|c|c|c|}
\hline 7 . & Kode & Nima Futirien \\
\hline$i$ & TाW & $\widehat{05}$ \\
\hline 2 & 1002 & DERLENCAPAN \\
\hline ) & 1001 & Futwo \\
\hline 1 & 8001 & SEDUNO \\
\hline 5 & 12000 & ENotraw \\
\hline 1 & 5000 & FERLLATAN \\
\hline$t$ & 2001 & FuTANOBAIK \\
\hline 8 & 3001 & $100 \mathrm{~N}$ \\
\hline 9 & 40001 & PENCARATIN \\
\hline 10 & 50001 & BuxagN \\
\hline 11 & 5000 & EAXAUT \\
\hline 12 & 8003 & EUAAPERLENCLAN \\
\hline 13 & 5000 & 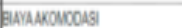 \\
\hline
\end{tabular}

Fig. 14: Estimates Report 


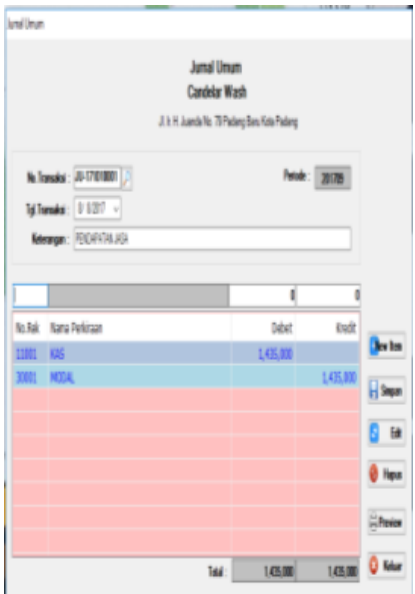

Fig. 15: General Jurnal View

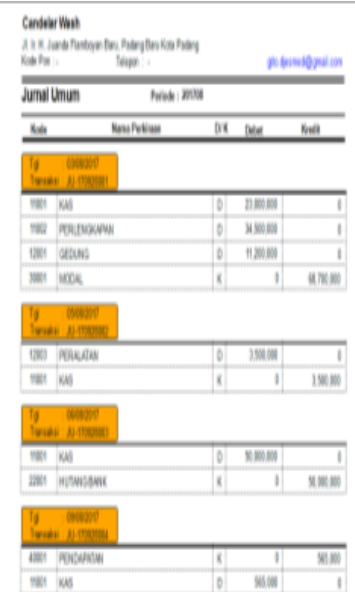

Fig. 16: General Jurnal Report

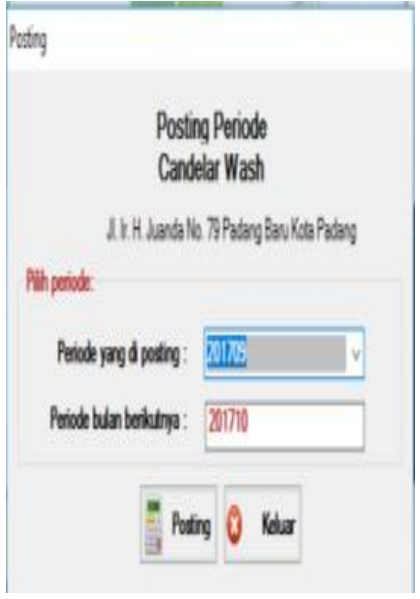

Fig. 17: Display Posting

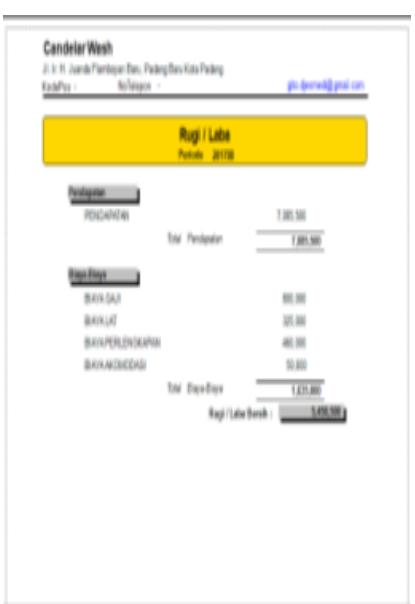

Fig. 18: Income Statement

\section{Conclusion}

The best service pricing can be done with fuzzy mamdani using matlab. In this way, micro business entrepreneurs can run their business better. This price determination greatly affects the amount of operating income.

Financial applications that have been built prove very helpful to entrepreneurs, because they can provide more accurate and fast financial statements. Business owners should know the financial of the business they are going through in order to make quick decisions on the financial statements.

\section{References}

[1] Adewuyi, P. A. (2012). Performance Evaluation of Mamdani-type and Sugeno-type Fuzzy Inference System Based Controllers for Computer Fan. International Journal of Information Technology and Computer Science, 5(1), 26-36. https://doi.org/10.5815/ijitcs.2013.01.03

[2] Agus Nursikuwagus. (2017). A Mamdani Fuzzy Model to Choose Eligible Student Entry. Telkomnika, , 15(1), 365-372. https://doi.org/10.12928/TELKOMNIKA.v15i1.4893

[3] Arcilla, M., Calvo-Manzano, J. A., \& San Feliu, T. (2013). Building an IT service catalog in a small company as the main input for the IT financial management. Computer Standards and Interfaces, 36(1), 42-53. https://doi.org/10.1016/j.csi.2013.07.003

[4] Basu, S. (2012). Realization of Fuzzy Logic Temperature Controller. International Journal of Emerging Technology and Advanced Engineering, 2(6), 151-155.

[5] Bergmeir, C., \& Ben, M. (2015). frbs : Fuzzy Rule-Based Systems for Classification. Journal of Statistical Software, 65(6), 1-30. https://doi.org/10.18637/jss.v069.i12

[6] Dauderis, H., \& Annand, D. (2017). with Open Texts Introduction to Financial Accounting.

[7] Faith, D. O., \& Edwin, A. M. (2014). A Review of The Effect of Pricing Strategies on The Purchase of Consumer Goods. International Journal of Research in Management, Science \& Technology, 2(2), 2321-3264.

[8] Lekhanya, L. M. (2013). Functions and Reliability of International Financial Reporting Systems of Rural Smes in Kwazulu Natal: Knowledge and Understanding of Financial Management. International Journal of Academic Research in Accounting Finance and Management Sciences, 3(3), 125-132. https://doi.org/10.6007/IJARAFMS/v3-i

[9] Liaquat, H., Irfan, A., \& Sami, A. (2017). Technical Efficiency And Its Determinants: A Case Study Of Faisalabad Textile Industry. City University Research Journal, Special Issue, 183-194 
[10] Ogedengbe, M. T., \& Agana, M. A. (2017). New Fuzzy Techniques for Real-Time Task Scheduling on Multiprocessor Systems, 47(3), 189-196.

[11] Patil, S., Mulla, A., \& Mudholkar, R. R. (2012). Best Student Award - a Fuzzy Evaluation Approach. International Journal of Computer Science and Communication, 3(1), 9-12.

[12] Sanchez-Torrubia, G., \& Torres-Blanc, C. (2010). A MamdaniType Fuzzy Inference System To Automatically Assess Dijkstra ' S Algorithm Simulation Gloria Sánchez - Torrubia , Carmen Torres - Blanc, 17(1).

[13] Shaharudin, J., Angely, G. S. N., Anita, J., \& Khin, T. M. (2012). Examining the Product Quality Attributes That Influences Customer Satisfaction Most When the Price Was Discounted: A Case Study in Kuching Sarawak Curtin University of Technology Sarawak Campus. International Journal of Business and Social Science, 3(23), 221-237.

[14] Sigit, H. T., \& Kapuji, A. (2014). Mamdani Fuzzy inference system Application Setting For Traffic Lights, 3(10), 56-62.

[15] Srismrita Basu. (2012). Realization of fuzzy logic temperatur Controller, 2(6), 56-62. 